\title{
Cartilage collagens: strategies for the study of their organisation and expression in the extracellular matrix
}

\author{
J Terrig Thomas, Shirley Ayad, Michael E Grant
}

The collagens constitute a family of proteins that are assembled into a variety of supramolecular structures in extracellular matrices. Research conducted over the last 20 years has led to the identification of at least 16 genetically distinct collagen types encoded by over 30 different genes. The structure, function and distribution of these collagens are still the subject of intense investigation, but on the basis of their known gene structure and amino acid sequences it is possible to classify them into different groups. The most studied group is that comprising the collagens capable of forming classical fibrous structures (types I, II, III, V and XI), whose main function is to resist tensile stresses exerted on tissues. Another class of collagenous molecules includes types IX, XII and XIV which are believed to be associated with the fibrous collagens and have been assigned the name of Fibril Associated Collagens with Interrupted Triple-helices (FACIT). Collagen types VIII and $\mathrm{X}$ appear to form another class of matrix proteins for they exhibit remarkable homology at the levels of gene organisation and amino acid sequence and have the ability to form regular hexagonal lattice structures. A detailed review of all collagen types is published elsewhere. ${ }^{1}$

Individual collagen types are rarely found in isolation in extracellular matrices and generally occur in conjunction with several others. For example, collagen types I, III, V and VI are widely distributed in connective tissues such as skin, tendon, aorta, gut etc. In contrast, collagen IV is localised exclusively to basement membranes and collagen VII has only been described in the anchoring fibrils underlying the lamina densa of many epithelia. During evolution a separate group of collagens has arisen to provide cartilaginous tissues with their own distinct macromolecular organisation. Here we find the cartilage-specific collagens (types II, IX, X and XI) together with the more ubiquitous collagen type VI, and possibly types XII and XIV (fig 1). There is still much to be discovered about the role of these collagens in cartilage and especially about their interactions with the highly hydrated proteoglycans of the cartilage matrix. The collagens must function not only to resist tensile forces and to distribute load on bones articulating in cartilaginous and synovial joints but also to mediate the growth and development of the skeleton. The critical role of collagen II in maintaining cartilage integrity has been demonstrated by studies on certain heritable chondrodysplasias, whereby aberrant collagen II synthesis gives rise to a spectrum of clinical symptoms ranging from mild dwarfism, myopia and secondary osteoarthritis (OA) in some forms of spondyloepiphyseal dysplasia (SED) to several lethal forms of achondroplasia. ${ }^{2}$ It is clear that the cartilage collagens are crucial determinants of the mechanical properties of all articulating joints and any disturbance of the complex collagenous

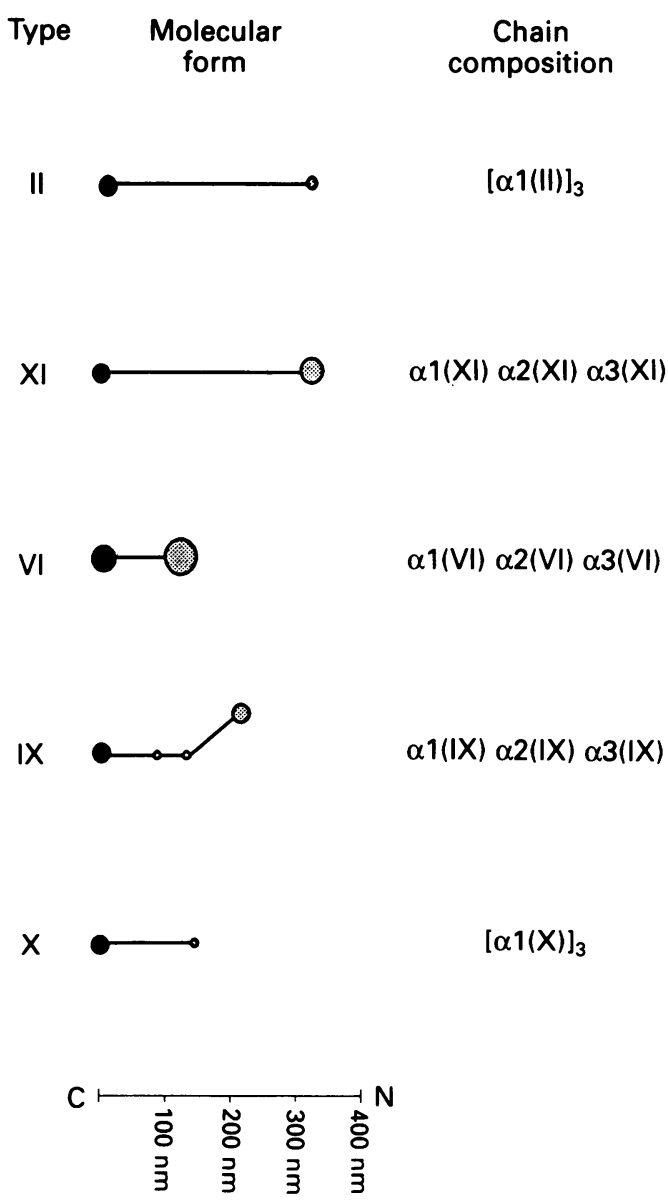

Figure 1 The molecular form and chain composition of the cartilage collagens. The molecular forms are represented by schematic scale diagrams with the triple helical domains drawn as thick black lines and the non-triple helical domains (NC) illustrated by filled or shaded circles. The molecules are orientated with their $\mathrm{NH}_{2}$-termini to the right. 
architecture is likely to lead to dysfunction and arthritic disease.

In this review we briefly discuss current knowledge of cartilage collagens and highlight how modern technologies are providing greater insight into cartilage collagen structure and function in health and disease.

\section{1) Collagen: a definition}

Over the past decade it has become increasingly difficult to define what is a collagen and what is not. Many of the collagens that do not constitute the major fibres of the extracellular matrix are hybrid molecules, where the collagenous domain may only be small in comparison to the non-collagenous part of the molecule. Others, for example type IX collagen, can be considered as protein cores of proteoglycans. However, the triple-helix, in which three left-handed helices ( $\alpha$ chains) twist around each other to form a right-handed superhelix, is common to all collagen types. Each $\alpha$ chain must contain glycine (Gly) at every third residue as this is the only amino acid small enough to fit into the centre of the triple-helix. Approximately $10-12 \%$ of each of the remaining $\mathrm{X}$ and $\mathrm{Y}$ residues of the repeating sequence $[\mathrm{Gly}-\mathrm{X}-\mathrm{Y}]_{\mathrm{n}}$ are proline and hydroxyproline respectively, hydroxyproline being essential for the formation of hydrogen bonds that stabilise the helix.

The fibril-forming collagens are synthesised as large precursor (procollagen) forms with non-collagenous propeptides at the $\mathrm{N}$ - and C-termini of an uninterrupted $300 \mathrm{~nm}$ triplehelix. The propeptides are removed completely in the case of types I, II and III collagens by specific $\mathrm{N}$ - and $\mathrm{C}$-proteinases before/during self-assembly and crosslinking of the triplehelical molecules into stable fibrils. Such fibrils exhibit the classical $x$ ray diffraction patterns of collagen. $^{3}$ Many of the newly discovered collagens do not fit entirely with the above criteria. For example, some collagens contain interrupted triple-helices and proteolysis leads to their fragmentation into shorter helical domains (types IV, VII, IX, XII and XIV). Others do not undergo the procollagen to collagen processing but retain their terminal non-collagenous domains which influence the supramolecular structures that they assume in the extracellular matrix (types IV, VI, VII, VIII, IX, X, XII and XIV).

\section{Collagen}

type

II

$X I+I I$

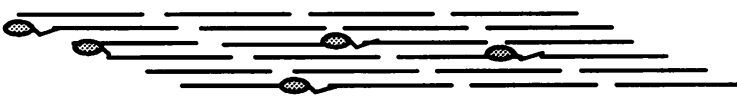

VI

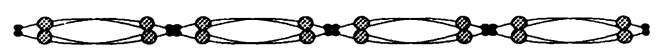

$|\mathrm{X}+1|$

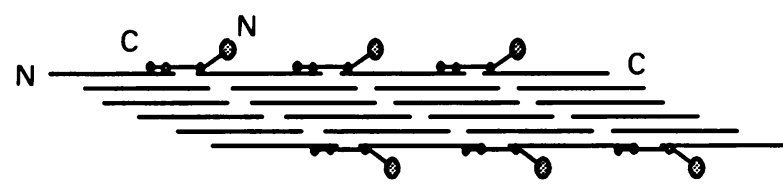

$x$

Supramolecular structure
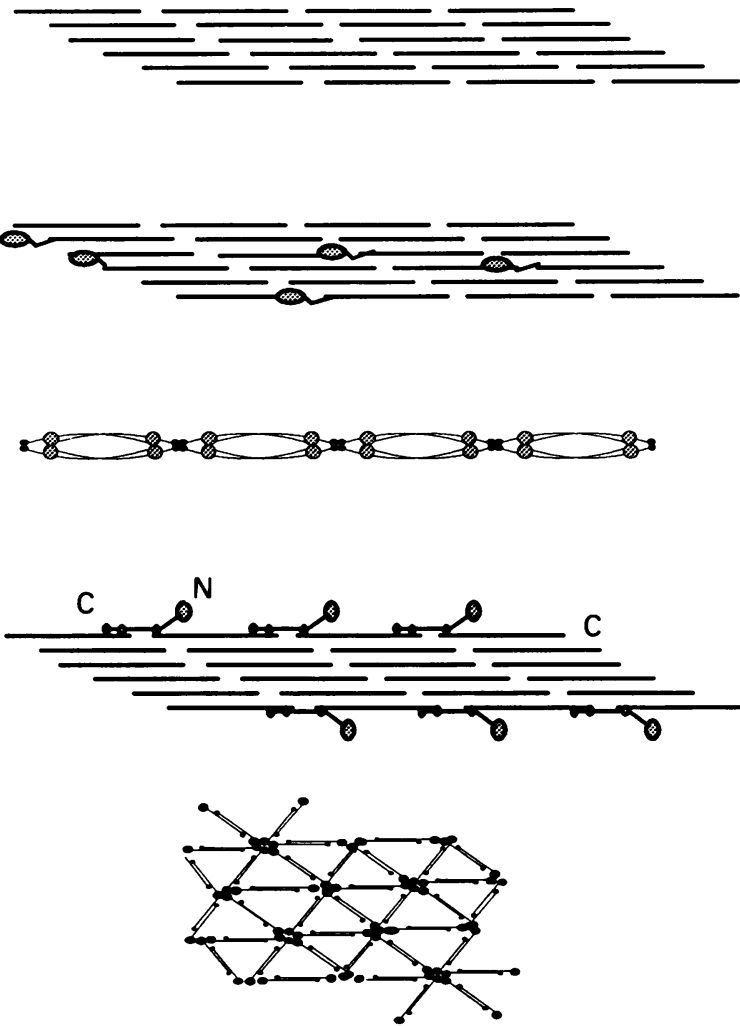

Figure 2 Diagramatic representation of the supramolecular assemblies adopted by the cartilage collagens. Unless otherwise indicated the molecules are orientated with their $\mathrm{NH}_{2}$-termini to the left. Type II collagen is organised into fibrils illustrated as an array of individual triple helices with a quarter-stagger of $67 \mathrm{~nm}$. Type XI collagen forms heterotypic fibrils with type II collagen (see text), but is distinguished from type II collagen by retaining the N-terminal NC domains as illustrated. Type VI collagen forms beaded microfibrils by antiparallel association of monomers into dimers, lateral association of dimers into tetramers and end-on association of tetramers. Type IX collagen does not form multimeric aggregates on its own, but associates, via cross-links, with the surface of type II collagen fibrils in an antiparallel fashion (see text). The globular NC4 domain and the triple helical COL3 domain project out from the fibril surface. Type $\mathrm{X}$ collagen molecules are thought to associate laterally and via their C-terminal NC domains to form a regular hexagonal lattice.
A) THE FIBROUS COLLAGENS: TYPES II AND XI Collagen type II is the major fibrous collagen found in cartilage as well as in other related tissues such as the vitreous humour of the eye and the intervertebral disc; and normally represents approximately $80-90 \%$ of the collagen content of the cartilage matrix. Type II collagen is closely associated with type XI which accounts for less than $5 \%$ of the cartilage collagen. As stated above type II and XI collagens are initially synthesised as soluble procollagen precursor molecules with noncollagenous amino- and carboxy-termini. In the case of type II collagen these peptides are removed by $\mathrm{N}$ - and $\mathrm{C}$-proteinase, respectively, before fibril formation, ${ }^{4}$ whereas, in type XI collagen all the $\mathrm{C}$-terminal non-collagenous domain, but only a proportion of the $\mathrm{N}$-terminal non-collagenous domain, is removed (fig 2 ). ${ }^{5}$

Type II collagen is a homotrimer $[\alpha 1(\mathrm{II})]_{3}$, whereas type XI collagen is a heterotrimer $[\alpha 1(\mathrm{XI}) \alpha 2(\mathrm{XI}) \alpha 3(\mathrm{XI})] .{ }^{5}$ The $\alpha 3$ chain of type $\mathrm{XI}$ collagen is probably the product of the same gene (COL2A 1 ) as that of $\alpha 1$ (II), although it is more glycosylated. Comparisons of the cDNA and gene sequences of the $\alpha 1(\mathrm{XI})^{6}$ and $\alpha 2(\mathrm{XI})^{7}$ chains with those of type $\mathrm{V}$ collagen $^{8}{ }^{9}$ have demonstrated striking similarities. Both type XI and type V collagen have been shown to form heterotypic fibrils with type II and type I collagen respectively ${ }^{10-12}$ and their retention of the $\mathrm{N}$-terminal non-collagenous domains is thought to restrict the overall diameter of these fibrils.

The structural similarities observed for the fibril-forming collagens are reflected at the gene level. They contain many discrete-sized exons of 54 bp or repeats thereof, with each 54 bp encoding 6 Gly-X-Y repeats. Consequently, it has been suggested that the fibrillar collagen 
genes evolved from a common 54 bp ancestral coding unit. ${ }^{13} 14$

Early studies on type II collagen demonstrated it had a higher hydroxylysine:lysine ratio and increased levels of glycosylated hydroxylysine than collagen types I and III. ${ }^{15}$ The function of the carbohydrate moieties remains unclear but there appears to be an inverse relationship between glycosylation and fibril diameter. ${ }^{16}$ Fibril diameter is clearly under careful control and glycosylation may explain, in part, why type II collagen forms much finer fibrils than type I collagen. However, in mammalian articular cartilage, fine fibrils $(10-25 \mathrm{~nm}$ ) are only found in the pericellular matrix immediately surrounding the chondrocytes, with much thicker fibrils occurring in the territorial and interterritorial matrices. ${ }^{17}$

It has recently been discovered that there are two alternatively spliced forms of type II collagen. A 207 bp 5'terminal exon (exon2) coding for a 69 amino acid sequence can either be spliced in (collagen type IIA) or out (collagen type IIB) of the procollagen mRNA in a tissue-specific manner. ${ }^{18}$ The domain encoded by the exon is conserved between the fibrillar collagens and may have a functional role in fibrillogenesis. In situ hybridisation studies have revealed that the exon is absent from the prool(II) mRNA species in fully differentiated cartilage and collagen IIA appears to be preferentially expressed by the cells of the perichondrium and in nonchondrogenic embryonic tissues such as nucleus pulposus of the developing intervertebral disc. ${ }^{18}$ Studies in the chick system have demonstrated collagen type IIA expression in pre-cartilage limb mesenchyme and also in non-cartilage tissues including embryonic calvaria, skin, heart, skeletal muscle and brain. ${ }^{19}$ No studies have yet been carried out to determine whether collagen type IIA is expressed in OA tissue.

\section{B) THE FACIT COLLAGENS: TYPES IX, XII AND} XIV

The major role of the collagen fibres of cartilage is to form a stable meshwork to counteract the swelling pressure generated by the hydrated proteoglycan aggregates. The achievement of stability requires the interaction of the collagen fibres with other matrix components and here the first FACIT collagen to be described (type IX collagen) may play a significant role.

Type IX collagen is a heterotrimer composed of three different $\alpha$ chains [ $\alpha 1$ (IX) $\alpha 2$ (IX) $\alpha 3$ (IX)] and is found associated with type II collagen. It contains three triple-helical collagenous domains (COL 1, 2 and 3 ) and four non-collagenous domains (NC1, to 4). Electron microscopical studies have demonstrated the localisation of type IX collagen along the surface of type II collagen fibrils with the COL 3 domain and the large (243 amino acids) NC4 domain projecting out from the fibril surface into the perifibrillar matrix. ${ }^{1020}$ The interaction between types II and IX collagens has been shown to be stabilised via cross-links ${ }^{21}$ and recent evidence suggests that the type IX and type II collagen molecules are arranged in an anti-parallel fashion $^{22}$ (fig 2). It has become apparent that the NC domains are of important structural significance. The large NC4 domain on the $\alpha 1$ (IX) chain is very basic, offering the possibility of interaction with acidic proteoglycan molecules. The $\alpha 2$ (IX) chain contains a NC3 domain which is 5 amino acids longer than the other two chains providing a flexible hinge region to the molecule and an attachment site for a glycosaminoglycan (GAG) side chain consisting of either chondroitin sulphate or dermatan sulphate. The GAG chain length is highly variable, is not present on all type IX collagen molecules in cartilage, ${ }^{23}$ and its role is presently unknown.

Types XII and XIV collagen are partially homologous to type IX collagen and their proposed function is to associate with type I collagen-containing fibrils in an analogous manner to the association between type IX and type II collagen. However, the precise nature of the interaction remains to be established. Types XII and XIV collagen are homotrimers containing two triple-helical domains (COL1 and COL2) and three non-collagenous domains (NC1 to NC3). ${ }^{24} 25$ The COL1 domain and part of the NC3 domain are homologous to the COL1 and NC4 domains of type IX collagen respectively. However, the NC3 domain of each $\alpha$ chain is very large, being $190 \mathrm{~K}$ in non-cartilaginous tissues, giving the molecules their characteristic cross-shape when viewed under the electron microscope by rotary shadowing. In cartilage, the NC3 domain of type XII collagen has recently been shown to be at least $200 \mathrm{~K}$ greater. ${ }^{26}$ There is also evidence indicating the presence of GAG in the NC3 domain of type XII collagen and in one of the other NC domains of type XIV collagen. ${ }^{26}$ Type XII collagen has been localised to the perichondrium at the articular surface and around cartilage canals whereas type XIV collagen is found throughout the matrix. ${ }^{26}$ Much is yet to be learned about the functional roles of this unusual family of collagenous extracellular matrix proteins.

\section{C) TYPE X COLLAGEN}

Type $\mathrm{X}$ collagen is a developmentally regulated short-chain collagen which is transiently expressed by hypertrophic chondrocytes at sites of endochondral bone formation. ${ }^{27} 28$ Such tissue-specific expression makes type $\mathrm{X}$ collagen a useful marker for both normal and aberrant bone formation. For example, in addition to its synthesis by developing long bones, type $\mathrm{X}$ collagen has also been localised in fracture repair callus ${ }^{29}$ and osteoarthritic joints. ${ }^{30} 31$ Type $\mathrm{X}$ collagen is unusual in that it is encoded by a condensed gene with approximately $95 \%$ of the coding sequence being contained in a large single exon. ${ }^{32} 33$ Type $\mathrm{X}$ collagen is a homotrimer with $\alpha$ chains of $M_{r} 59000$ and a helical domain of $M_{r}$ 
45000 , approximately half the size of $\alpha 1$ (II) chains. Studies in vitro carried out mainly on chick type $\mathrm{X}$ collagen have demonstrated that it has a triple-helical domain of approximately $130 \mathrm{~nm}^{34}$ and is capable of forming a hexagonal lattice-like structure ${ }^{35}$ similar to that observed for the genetically-related type VIII collagen in Descemet's membrane. ${ }^{36}$ Unlike the fibrillar collagens, type $\mathrm{X}$ collagen retains its noncollagenous $\mathrm{C}$ - and $\mathrm{N}$-terminal domains and the hexagonal lattice-like structure can be visualised as regularly spaced nodules of aggregated C-termini interconnected with filamentous structures formed via interactions between adjacent triple-helices (fig 2). ${ }^{35}$ The potential involvement of such structures in the mineralisation of hypertrophic cartilage and the endochondral ossification process remains to be defined.

D) TYPE VI COLLAGEN

Type VI collagen forms a distinct sub-class within the collagen family and assembles into

Non-collagenous proteins isolated from cartilage

\begin{tabular}{|c|c|c|c|}
\hline Protein & Localisation & Function & Reference \\
\hline $\begin{array}{l}\text { Anchorin CII } \\
\left(\mathrm{M}_{\mathrm{r}} 34000\right)\end{array}$ & $\begin{array}{l}\text { Chick chondrocyte cell } \\
\text { surface }\end{array}$ & Binds type II collagen & 43,44 \\
\hline $\begin{array}{l}\text { Cartilage matrix protein } \\
\text { CMP } \\
\left(M_{\mathrm{r}} 148000 \text { homotimer }\right. \\
\left.\text { subunit } \mathrm{M}_{\mathrm{r}} 54000\right)\end{array}$ & $\begin{array}{l}\text { Bovine tracheal and } \\
\text { epiphyseal cartilage, } \\
\text { nasal septum, not } \\
\text { articular cartilage }\end{array}$ & $\begin{array}{l}\text { Interacts with } \\
\text { proteoglycans and binds } \\
\text { type II collagen }\end{array}$ & 45,46 \\
\hline $\begin{array}{l}\text { Cartilage matrix protein } \\
\left(\mathrm{M}_{\mathrm{r}} 36000 \text { monomeric }\right)\end{array}$ & Articular cartilage & Not known & 45 \\
\hline $\begin{array}{l}\text { Chondrocalcin (C- } \\
\text { propeptide of type II } \\
\text { collagen) } \\
\left(M_{\mathrm{r}} 105000 \text { homo- }\right. \\
\text { trimer, subunits } \mathrm{M}_{\mathrm{r}} \\
35000)\end{array}$ & Hypertrophic cartilage & $\begin{array}{l}\text { Binds hydroxyappatite. } \\
\text { Possible role in cartilage } \\
\text { mineralisation }\end{array}$ & 47 \\
\hline $\begin{array}{l}\text { Collagen-binding } \\
\text { protein CBP } \\
\left(M_{\mathrm{r}} 54000\right)\end{array}$ & $\begin{array}{l}\text { Swarm chondrosarcoma } \\
\text { Cartilage }\end{array}$ & $\begin{array}{l}\text { Binds type II collagen } \\
\text { and interacts with } \\
\text { proteoglycans. } \\
\text { Possible role in } \\
\text { regulating collagen fibril } \\
\text { diameter }\end{array}$ & 48 \\
\hline $\begin{array}{l}\text { Cartilage matrix } \\
\text { glycoprotein (CMGP) } \\
\left(\mathrm{M}_{\mathrm{r}} 550000 \text { tetramer, }\right. \\
\text { subunits } \mathrm{M}_{\mathrm{r}} 116000- \\
130000)\end{array}$ & $\begin{array}{l}\text { Articular cartilage } \\
\text { Fibrocartilage } \\
\text { Vitreous }\end{array}$ & Not known & 49 \\
\hline $\begin{array}{l}\text { Cartilage oligomeric } \\
\text { matrix protein (COMP) } \\
\text { Similar/identical to } \\
\text { CMGP } \\
\left(M_{\mathrm{r}} 524000 \text { pentamer, }\right. \\
\left.\text { subunits } M_{\mathrm{r}} 100000\right)\end{array}$ & $\begin{array}{l}\text { Swarm chondrosarcoma } \\
\text { Cartilage }\end{array}$ & Not known & 50 \\
\hline $\begin{array}{l}\text { Ch21 protein } \\
\left(M_{\mathrm{r}} 21000\right) \\
\text { Identical to } \mathrm{p} 20 \mathrm{~K} \\
\text { protein }\end{array}$ & $\begin{array}{l}\text { Chondrocytes and } \\
\text { granulocytes undergoing } \\
\text { terminal differentiation }\end{array}$ & $\begin{array}{l}\text { Not known } \\
\text { (binding and transport } \\
\text { of small hydrophobic } \\
\text { molecules?) }\end{array}$ & 51 \\
\hline $\begin{array}{l}\text { Chondronectin } \\
\left(M_{\mathrm{r}} 180000 \text {, subunits }\right. \\
\left.M_{\mathrm{r}} 56000-77000\right)\end{array}$ & Cartilage and serum & $\begin{array}{l}\text { Mediates attachment of } \\
\text { chondrocytes to type II } \\
\text { collagen }\end{array}$ & 52 \\
\hline $\begin{array}{l}\text { Fibromodulin } \\
\left(M_{\mathrm{r}} 59000\right) \\
\text { Structurally related to } \\
\text { decorin and } \mathrm{PG}-S 1\end{array}$ & $\begin{array}{l}\text { Cartilage and other } \\
\text { connective tissues }\end{array}$ & $\begin{array}{l}\text { Collagen binding } \\
\text { regulation of } \\
\text { fibrillogenesis }\end{array}$ & 53,54 \\
\hline $\begin{array}{l}\text { Fibronectin } \\
\left(M_{r} 440000\right)\end{array}$ & Most tissues & $\begin{array}{l}\text { Binds to chondrocytes } \\
\text { and type II collagen }\end{array}$ & 55,56 \\
\hline$M_{r} 58000$ & $\begin{array}{l}\text { Bovine articular cartilage } \\
\text { Other tissues? }\end{array}$ & Not known & 53 \\
\hline $\begin{array}{l}M_{r} 55000 \text { (monomer) } \\
\text { Similar to } M_{r} 58000\end{array}$ & $\begin{array}{l}\text { Adult human articular } \\
\text { cartilage }\end{array}$ & $\begin{array}{l}\text { Not known } \\
\text { (Immunoglobulin } \\
\text { binding?) }\end{array}$ & 57 \\
\hline $\begin{array}{l}\text { PARP (Proline/Arginine } \\
\text { Rich Protein) } \\
M_{\mathrm{r}} 24000 \text { monomer } \\
49 \% \text { identical to } \\
\text { N-term. end of } \alpha 1 \text { (XI) }\end{array}$ & Cartilage & Not known & 58 \\
\hline $\begin{array}{l}\text { Tenascin } \\
\left(M_{\mathrm{r}}>10^{6} \text { daltons }\right)\end{array}$ & & Binds to aggrecan & 59 \\
\hline
\end{tabular}

beaded microfibrils which occur in cartilage and in a number of other tissues including aorta, placenta, uterus, skin, tendon and cornea. It has a relatively short triple-helical domain $(105 \mathrm{~nm})$ flanked by exceptionally large $\mathrm{N}$ - and $\mathrm{C}$-terminal globular domains that account for more than two thirds of the mass of the molecule (fig 1). Three distinct $\alpha$ chains have been attributed to type VI collagen although there is evidence that all three are not coordinately expressed and there may be a family of collagen VI isoforms. ${ }^{37}$ The most common form is the heterotrimer $[\alpha 1(\mathrm{VI})$ $\alpha 2(\mathrm{VI}) \alpha 3(\mathrm{VI})]$, where the $\alpha 1(\mathrm{VI})$ and $\alpha 2(\mathrm{VI})$ chains have $M_{\mathrm{r}} 140 \mathrm{~K}$ and share some sequence homology, and the unrelated $\alpha 3(\mathrm{VI})$ chain has $M_{r} 240-280 \mathrm{~K}$. The larger size of the $\alpha 3$ (VI) chain is accounted for by a much larger $\mathrm{N}$-terminal non-collagenous domain which is subject to variation as a result of alternative splicing of the $\alpha 3$ (VI) mRNA. ${ }^{38} 39$

The structure adopted by type VI collagen is very different from other collagen types. Following its synthesis, monomers assemble intracellularly into antiparallel staggered dimers, two of which in turn align in register to form a tetramer. Following secretion, end to end polymerisation of the tetrameric units results in the formation of typical microfibrillar networks (fig 2).

The function of type. VI collagen is illdefined, but it possesses a number of interactive properties which suggest it may have a bridging role between cells and their extracellular matrix. The triple-helical domain of type VI collagen contains a number of sequences capable of supporting cell binding (Arg-Gly-Asp or RGD) but although it has been shown to bind to cells, at present it is not known which of the RGD sequences are involved. The type VI collagen microfibrils have been shown to be stabilised by specific non-covalent interactions with hyaluronan ${ }^{40}$ and type VI collagen has also been shown to interact with collagen types I and II, and the small proteoglycan decorin. ${ }^{41}$ The globular domains of type VI collagen contain repetitive 200 amino acid motifs [three in $\alpha 1$ (VI) and $\alpha 2(\mathrm{VI})$ and 11 in $\alpha 3(\mathrm{VI})$ ] which share a high degree of homology to the fibrillar collagen-binding A domains in von Willebrand factor. $^{42}$

E) NON-COLLAGENOUS PROTEINS

Collagens, virtually by definition, are assigned a structural role in cartilaginous tissues but in addition to the proteoglycans there also exists a number of other proteins which may play key structural roles. Some of the proteins have defined functions but, for many, their function remains unknown. It is beyond the scope of the present review to give a detailed account of all the proteins isolated to date but some brief information is included in the table. The defined ultrastructure of the cartilage matrix therefore is undoubtedly complex and there is still much work to be done to determine the specific mechanisms by which matrix assembly takes place. 


\section{2) Current strategies in the study of the collagens in normal and diseased cartilage}

To enhance our understanding of cartilage structure and the complex interplay between cells and matrix that occur in this avascular tissue, a variety of techniques have been developed. A brief synopsis of the basic strategies currently in use in the study of cartilage collagens is outlined below.

\section{A) BIOCHEMICAL EXTRACTION}

Although the existence of 'collagen' in connective tissues has been known since the nineteenth century it was not until the $1950 \mathrm{~s}$ that the structure of type I collagen was defined ${ }^{60}$ followed by type II collagen in the late $1960 \mathrm{~s} .{ }^{61}$ The early studies on chick sternal cartilage demonstrated that type II collagen, which is not readily solubilised in neutral salt solutions, can be extracted following limited pepsin digestion. ${ }^{62}$ Such a relatively crude procedure relies on the fact that collagens comprise three polypeptides in a triple-helical conformation which is resistant to proteolytic cleavage. The other cartilage collagens have since been successfully extracted using similar, but more elaborate adaptations. Extraction of collagens from mature mammalian cartilages requires preliminary extraction of the proteoglycans with dissociative agents such as $4 \mathrm{M}$ guanidinium hydrochloride to ensure a more efficient solubilisation of the collagens by pepsinisation. Differential salt fractionation of the pepsin digests at acid $\mathrm{pH}$ can readily separate out the different collagen types. A detailed breakdown of the fractionation of pepsin-solubilised collagens from cartilage has been given elsewhere..$^{63}$ Analyses of the major fibrillar cartilage collagen types are particularly amenable to such extraction procedures. However, the helical domain of collagen VI represents less than $30 \%$ of the native molecule and fragmentation of collagen IX arises due to proteolytic cleavage at the non-collagenous (NC) domains separating the helical segments. Consequently, alternative methods for the extraction of the intact forms of these cartilage collagens have had to be developed. ${ }^{64}{ }^{65}$

Biochemical extraction has allowed much information to been gained into the macromolecular composition and gross quantities of particular collagen types in normal and diseased cartilage, but the approach does have its limitations. The procedures are lengthy and require relatively large amounts of tissue which restricts the application of studies on small animal model systems of cartilage disease where early phases of damage and repair can be observed. In contrast, human material is normally available only from severely affected joints and therefore it is only the resultant endstage of the disease that is being studied.

B) IMMUNOLOCALISATION

Immunocytochemical studies commonly use indirect immunofluorescence in which the antigenic epitopes are visualised by an enzymic system coupled to a development of a coloured end product which is recognised by light microscopy. To achieve greater definition, antigenic epitopes can be recognised by electron microscopy by using a second antibody coupled to colloidal gold.

Immunolocalisation can provide valuable information on the temporal and spatial deposition of various matrix proteins. The extraction and subsequent purification of particular collagen types has permitted collagen type-specific antibody production for use in studies such as immunolocalisation. Although antibodies to type I and II collagens are now commercially available, the production of antibodies which specifically recognise the other minor cartilage collagens has proved to be a more difficult task. The helical domains of collagen molecules usually give only a weak immunological response when injected into rabbits or other species. However, the non-collagenous extension peptides have proved to be much more immunogenic. Polyclonal antibodies can be readily raised to purified collagens but the structural similarity between the triple helical domains requires that they be cross-absorbed against other known collagen types. This approach is becoming increasingly difficult as more and more collagens are being discovered. Monoclonal antibodies, demonstrating high specificity and affinity for the initial immunogen, represent an alternative strategy in antibody production technology. Unfortunately, most monoclonal antibodies raised to the various collagen types also show a high degree of species specificity so that antibodies raised against a collagen type from one species may not cross-react/recognise its human counterpart. Caution must always be exercised when using monoclonal antibodies in immunolocalisation studies as it is possible that the single epitope recognised may be masked for example, by interactions between other matrix macromolecules or by mineral. It is often a prerequisite to de-calcify tissue sections before subsequent immunolocalisation. Due to epitopes being conformationally determinant, it is essential that the antibody is known to recognise the native protein. This will depend largely on the biochemical extraction procedure adopted during the initial purification of the immunogen.

Biochemical and immunolocalisation analyses of surgically removed joints from patients with later stages of $\mathrm{OA}$ give some insight into the resultant effect of cumulative changes within the joint over a number of years. Although this information is useful, in order to identify the root cause of the disease it is necessary to obtain tissue at a much earlier stage. Animal models can be used, but it is very often difficult to extrapolate the results back to humans. The removal of small cartilage samples by arthroscopy from patients with early OA should allow subsequent analyses by in situ hybridisation and immunolocalisation. 
C) MEASUREMENT OF COLLAGEN BREAKDOWN There are comprehensive data documenting proteoglycan degradation in $\mathrm{OA}$ but there is little understanding of what happens to the collagens. The distinctive features of collagenous proteins such as their relatively high content of hydroxyproline, hydroxylysine and pyridinium cross-links have provided useful urinary and/or serum markers for detecting abnormal cartilage/bone degradation. Hydroxyproline, the most common marker studied, ${ }^{66}$ is extremely non-specific due to the possibility of it arising in body fluids from several sources including the $\mathrm{Clq}$ complement component and from the high proportions of newly synthesised collagen which are degraded intracellularly. ${ }^{67}$ Urinary levels of pyridinium cross-links, which are present in mature collagen fibrils, have been shown to correlate with severity of $\mathrm{OA}^{68}$ and may provide a means of monitoring disease progression and therapy. Analysis of synovial fluid for such markers can indicate collagen breakdown in specific joints since the fragments formed following degradation are not interacting with other matrix macromolecules and are free to diffuse out into the synovial fluid. Assays have not yet been developed to detect degradation products of collagen types VI, IX, X, XI, XII or XIV which may appear in synovial fluid or serum following the breakdown of the fibrillar collagen meshwork.

A major limitation in detecting and studying collagen degradation in normal and OA joints has been the lack of a technique for identifying collagen breakdown in situ. Recently, antibodies have been raised which specifically recognise only fragmented and denatured type II collagen $\alpha$ chains. ${ }^{69}$ Immunolocalisation studies have demonstrated that staining for denatured type II collagen is much greater in arthritic cartilage and has a different distribution pattern to that in normal tissue. It is conceivable that the levels of denatured fragments of type II collagen in the synovial fluid of affected joints may correlate well with the extent of disease. If so, then the ability to detect them specifically would provide a sensitive marker system.

D) IN VITRO SYSTEMS

In vitro culture experiments on chondrocytes or cartilage explants accompanied by SDSPAGE analysis of $\left[{ }^{3} \mathrm{H}\right]$ proline-labelled biosynthetic products have been extremely valuable in providing an insight into the nature of collagen precursors, their processing and deposition in the extracellular matrix. ${ }^{63}$ The effects of various growth factors and cytokines on collagen gene expression are most readily investigated using in vitro systems but are subject to the criticism that chondrocytes in vivo do not exist in monolayers on plastic bathed in serum. Consequently attempts have been made to develop culture systems having somewhat more biologically-relevant environments. Chondrocytes cultured within 3-D collagen gels ${ }^{70}$ or over agarose ${ }^{71}$ have been shown to exhibit a rounded cell morphology, elaborate an extracellular matrix containing cartilage collagens and maintain their phenotype for longer periods than those cultured on plastic. Manipulation of the surrounding matrix by incorporation of other components into the collagen gel system such as collagen II, proteoglycan aggregates and calcium salts have been shown to have profound effects on embryonic chondrocyte collagen gene expression ${ }^{72-74}$ It remains to be established whether cells from mature cartilage can respond to external factors in a similar manner. However, studies on OA cartilage have demonstrated the presence of at least three different chondrocyte phenotypes expressing different patterns of collagenous polypeptides. ${ }^{32}$ There is undoubtedly a need to develop in vitro systems whereby the effects of factors, particularly those known to be elevated in OA tissue, can be examined on immortalised chondrocytes exhibiting a stable phenotype. The availability of stable chondrocyte cell lines would also benefit molecular biological approaches such as the study of DNA-protein interactions controlling and modulating collagen gene expression. The isolation of sufficient nuclear proteins for performing DNA footprinting and gel retardation assays requires large numbers of cells with a defined phenotype. Cell lines have been produced by infection of fetal rat costal chondrocytes with viruses carrying the $m y c$ and raf oncogenes ${ }^{75}$ or by transfection of rabbit articular chondrocytes with a plasmid containing the SV40 early function segment. ${ }^{76}$ However, the immortalised cells produced only maintain some of the properties of differentiated chondrocytes. The main problem with current methods of cell immortalisation is that they rely on the random integration of the responsible gene into the host genome leading to the possibility of it having adverse effects on the expression of certain host cell genes. Studies on the molecular mechanisms involved in cellular immortalisation will hopefully provide a means of producing more reliable cell lines in the future. Alternatively, cells from chondrosarcomas may be of value to in vitro analyses provided they are able to respond to external stimuli in a manner similar to normal chondrocytes. Karyotyping of such cells is essential due to a number of chondrosarcomas having been shown to contain chromosomal translocations. ${ }^{77}$

The elucidation of the mechanisms regulating the complex interactions between different collagen types and between collagens and other extracellular matrix components in vivo is still in its infancy. For example, although the longitudinal packing of fibrillar collagen molecules into a quarter-stagger array has been known for a long time, much less is known about the lateral packing of collagen molecules to form circular crosssectioned fibrils of uniform diameter. However, advances have been made with the development of an in vitro system for generating collagen fibrils by enzymic cleavage of type I procollagen with purified procollagen 
C-terminal proteinase. ${ }^{78} 79$ The technique has provided an insight into fundamental aspects of collagen fibril formation and has been successfully applied to the study of abnormal type I collagen fibrils produced by patients with osteogenesis imperfecta ${ }^{80}$ It is conceivable that similar studies could be carried out on type II collagen from patients with genetically inherited OA showing linkage to COL2A1. Whether such systems can be exploited to gain a better understanding of overall matrix assembly involving multiple macromolecular components remains to be established.

E) MOLECULAR BIOLOGICAL APPROACHES Reports of the first cloned collagen DNA sequences appeared over a decade ago $^{81}$ and since then rapid progress has been made in the isolation, characterisation and chromosomal localisation of all the genetically distinct collagens discovered to date. ${ }^{82}$ Complementary DNA (cDNA) probes have proved to be an extremely useful and sensitive tool for determining the levels of collagen gene expression (as measured by the level of specific mRNA) and the sites of collagen synthesis (by in situ hydridisation).

Steady-state mRNA levels for a given gene can be estimated by transferring known amounts of either total RNA or polyA RNA extracted from a tissue sample onto nylon on nitrocellulose membranes (Northern or slot blot) followed by hydridisation to a labelled probe. The technique is limited by its requirement of microgram quantities of RNA which may not be readily available from a clinically removed sample. However, the development of the polymerase chain reaction (PCR) has provided a method for the detection of mRNA species from small amounts of tissue. ${ }^{83}$ Essentially, RNA extracted from the tissue is reverse transcribed into cDNA and amplified by consecutive rounds of annealing of specific oligonucleotide primers, elongation of the target sequence using Taq DNA polymerase and denaturation of the doublestranded product. Due to the primer extension products from one cycle acting as templates in the next, the copy number approximately doubles at every cycle so that 20 cycles of PCR yields about a million-fold amplification. Unfortunately, the sensitivity and simplicity of the technique is not matched by quantitative accuracy. Anything capable of interfering with the exponential amplification effectively nullifies any quantitative assessment of the end products. However, PCR can be a quantitative procedure if appropriate internal controls are used and precautions are taken to minimise the amount of interference with the doubling of the target sequence. ${ }^{84}$ Quantitative PCR therefore, could potentially be of great use in measuring the gene expression of a variety of collagenous and non-collagenous proteins from limited amounts of OA tissue.

In situ hybridisation is also a highly sensitive technique, allowing the detection of gene expression by individual cells by hybridisation of CDNA probes to suitably prepared tissue sections. Since the functional half-life of many mRNAs is relatively short (minutes or hours) their detection in situ can allow for an accurate assessment of the temporal and spatial expression of a given gene. It should be emphasised, however, that the transcription of a gene and its subsequent translation are two independently controlled events and consequently any data obtained by in situ hybridisation can only be substantiated by concomitant immunolocalisation of the gene product. This should also be taken into account with results from quantitative PCR and Northern and slot blot analyses. To ascertain whether the level of gene transcription is equivalent to its translation in situ hybridisation and immunolocations should be performed on serial sections ${ }^{31}{ }^{32}$ and ideally, the techniques should be combined to allow for simultaneous localisation of the mRNAs and their respective gene products. It is not yet possible to carry out such a study on mineralised cartilage tissue, although a method has been described for a cell culture system. ${ }^{85}$

The application of recombinant DNA technology to the study of cartilage collagen gene expression has so far led to only a relatively basic understanding of the mechanisms involved in collagen gene regulation and many areas remain to be investigated. For example, little is known of how multiple DNA sequences and transcription factors interact to modulate the level of gene transcription. An understanding of such regulatory mechanisms is essential for both elucidating normal patterns of collagen gene expression in endochondral bone formation and aberrant gene expression in OA. Ultimately, it may be possible to alter the controlling mechanisms of and stimulate the formation/regeneration of cartilage in diseased tissue.

F) TRANSGENIC ANIMALS

The latest and perhaps most far reaching technology which will benefit the study of OA is that of transgenics. Any gene which has been cloned and sequenced can potentially be manipulated in the germ line, usually of mice, enabling more precise information to be gained about its function. Homologous recombination of the gene of interest into embryonic stem cells is currently the most effective method for ensuring that the gene is expressed at the correct genomic locus. ${ }^{86}$ The mice which subsequently develop from this procedure are chimeric heterozygotes; mating of siblings allows the creation of a homozygous founder line carrying the mutant gene.

The mechanical properties of bone and cartilage are functions of the molecular organisation of their extracellular matrices, and $\mathrm{OA}$ involves a malfunction of that structure. Consequently, the creation of transgenic mice harbouring defects in specific structural components may predispose them to early onset of OA. However, the use of transgenics in the study of cartilage matrix function is still in its infancy. To date transgenic mice have 
been produced harbouring minigene constructs of $\alpha 1$ (II), ${ }^{87} \alpha 1(\mathrm{IX}){ }^{88}$ and $\alpha 1(\mathrm{X}) .{ }^{89}$ Each study has employed the method of microinjection into pronuclei of one cell mouse embryos for the introduction of the construct into the mouse genome. This method which relies on the random integration of the minigene into a site favourable for its transcription is highly inefficient. Consequently caution should be taken in drawing conclusions from the phenotypes obtained as it is possible that the integrated construct may have disrupted the expression of another gene. A prerequisite therefore when studying mice harbouring cartilage-specific transgenes is that the expression of the construct is restricted to cartilagenous tissues. When the minigene pro $\alpha$ chains are coexpressed in the presence of normal pro $\alpha$ chains they associate together. However, the mutant collagen produced is rapidly degraded intracellularly due to incorrect folding and the inability to form a stable triple helix, a process referred to as 'procollagen suicide'. ${ }^{90}$ Transgenic mice harbouring the type II and type $\mathrm{X}$ minigenes showed varying forms of chondrodysplasia ${ }^{87} 89$ whereas histological analyses of those harbouring the type IX collagen minigene showed the presence of early onset of $\mathrm{OA}$ in the knee joint and corneal disorders. ${ }^{88}$

Although the results obtained from the limited number of studies described above are preliminary, there is clearly a significant contribution to be made from transgenics to the study of cartilage matrix. In addition to being able to examine the functional roles of the non-fibrillar collagens it will also be possible to use cartilage collagen-specific promoters to drive the expression of other factors much implicated in controlling matrix synthesis and degradation. Such factors could include the cartilage-degrading enzymes, which are known to be elevated in OA tissue, ${ }^{91}{ }^{92}$ and their inhibitors, as well as various cytokines and growth factors. As transgenic technology improves, it will be of great interest to discover the extent to which transgenic animals can contribute towards the understanding of the pathological processes involved in OA.

1 Kielty C M, Hopkinson I, Grant M E. The collagen family: structure, assembly, and organization in the extracellular matrix. In: Royce P M, Steinmann B, eds. Connective tissue and its heritable disorders. New York: Wiley-Liss, tissue and $103-47$.

2 Byers P H. Molecular heterogeneity in chondrodysplasias. Am 7 Hum Genet 1989; 45: 1-4.

3 Ramachandran G N, Kartha G. Structure of collagen. Nature 1954; 174: 269-70.

4 Peltonen L, Halila R, Ryhanen L. Enzymes converting procollagens to collagens. $\mathcal{F}$ Cell Biochem 1985; 28: 167-73.

5 Morris N P, Bachinger H P. Type XI collagen is heterotrimer with the composition $(1 \alpha, 2 \alpha, 3 \alpha)$ retaining non-triple-helical domains. F Biol Chem 1987; 262: $11345-50$.

6 Bernard $\mathrm{M}$, Yoshioka $\mathrm{H}$, Rodriguez $\mathrm{E}$, et al. Cloning and sequencing of pro- $\alpha 1(\mathrm{XI})$ collagen cDNA demonstrates that type XI belongs to the fibrillar class of collagens and reveals that the expression of the gene is not restricted to cartilagenous tissue. $\mathcal{F}$ Biol Chem 1988; 263: 17159-66.

7 Kimura T, Cheah K S E, Chan S D H, et al. The human $\alpha 2(\mathrm{XI})$ collagen (COLIIA2) chain. Molecular cloning of $\alpha 2(\mathrm{XI})$ collagen (COLIIA2) chain. Molecular cloning of cDNA and genomic DNA reveals characteristics of a fibrillar collagen with differences in

8 Takahara K, Sato Y, Okazawa N, et al. Compete primary structure of human collagen $\alpha 1(V)$ chain. $\mathcal{F}$ Biol Chem 1991; 266: 13124-9.
9 Greenspan D S, Cheng W, Hoffman G G. The pro- $\alpha 1$ (V) collagen chain: complete primary structure, distribution of expression, and comparison with the pro- $\alpha 1(\mathrm{XI})$ collagen chain. $f$ Biol Chem 1991; 266: 24727-33.

10 Vaughan L, Mendler M, Huber S, et al. D-periodic distribution of collagen type IX along cartilage fibrils. f Cell Biol 1988; 106: 991-7.

11 Mendler M, Eich-Bender S, Vaughan L, Winterhalter K H, Bruckner P. Cartilage contains mixed fibrils of collagen types II, IX and XI. F Cell Biol 1989; 108: 191-7.

12 Birk D E, Fitch J M, Babiarz J P, Doane K J, Linsenmayer $T F$. Collagen fibrillogenesis in vitro: interaction of types I and V collagen regulates fibril diameter. $\mathcal{F}$ Cell Sci 1990; 95: 649-57.

13 Yamada Y, Avvedimento V E, Mudryj M, et al. The collagen gene: evidence for its evolutionary assembly by amplification of a DNA segment containing an exon of 54 bp. Cell 1980; 22: 887-92.

14 Exposito J-Y, Garrone R. Characterization of a fibrillar collagen gene in sponges reveals the early evolutionary appearance of two collagen gene families. Proc Natl Acad Sci USA 1990; 87: 6669-73.

15 Miller E J. Isolation and characterization of a collagen from chick cartilage containing three identical $\alpha$-chains. Chick cartilage containing

16 Grant M E, Jackson D S. The biosynthesis of procollagen. Essays. Biochem 1976; 12: 77-113.

17 Poole C A, Flint M H, Beaumont B W. Morphological and functional interrelationships of articular cartilage matrices. F Anat 1984; 138: 113-38.

18 Sandell L J, Morris N, Robbins J R, Goldring M B. Alternatively spliced type II procollagen mRNAs define distinct populations of cells during vertebral development: differential expression of the aminopropeptide. $\mathcal{F}$ Cell Biol 1991; 114: 1307-19.

19 Nah H-D, Upholt W B. Type II collagen mRNA containing an alternatively spliced exon predominates in the chick limb prior to chondrogenesis. F Biol Chem 1991; 266: $23446-52$.

20 Muller-Glauser W, Humbel B, Glatt $M$, Strauli $P$, Winterhalter K H, Bruckner P. On the role of type IX collagen in the extracellular matrix of cartilage: type IX collagen is localised to intersections of collagen fibrils. fCell Biol 1956: 102: 1931-9.

21 Eyre D R, Apron S, Wu J-J, Ericsson L H, Walsh K A. Collagen type IX: evidence for covalent linkages to type II collagen in cartilage. Febs Lett 1987; 220: type II

22 Wu J-J, Woods P E, Eyre D R. Identification of cross-linking sites in bovine cartilage type IX collagen reveals an antiparallel type II-type IX molecular relationship and type IX to type IX bonding. $F$ Biol Chem 1992; 267: 23007-14.

23 Ayad S, Marriott A M, Brierley V H, Grant M E. Mammalian cartilage synthesizes both proteoglycan and non-proteoglycan forms of type IX collagen. Biochem $\mathcal{f}$ 1991; 278: 441-5.

24 Gordon M K, Gerecke D R, Nishimura I, Ninomiya Y, Olsen B R. A new dimension in the extracellular matrix. Connect Tiss Res 1989; 20: 179-86.

25 Dublet B, van der Rest M. Type XII collagen is expressed in embryonic chick tendons: isolation of pepsin-derived fragments. F Biol Chem 1991; 266: 6853-8.

26 Watt S L, Lunstrum G P, McDonough A M, Keene D R, Burgeson R E, Morris N P. Characterization of collagen types XII and XIV from foetal bovine cartilage. $\mathcal{F}$ Biol Chem 1992; 267: 20093-9.

27 Schmid T M, Linsenmayer T F. Immunohistochemical localization of short-chain cartilage collagen (type $\mathrm{X}$ ) in avian tissues. $\mathcal{F}$ Cell Biol 1985; 100: 598-605.

28 Kwan A P L, Freemont A J, Grant M E. Immunoperoxidase localization of type $\mathrm{X}$ collagen in chick tibiae. Biosci Rep 1986; 6: 155-62

29 Grant W T, Wang G-J, Balian G. Type X collagen synthesis during endochondral ossification in fracture repair. $\mathcal{F}$ Biol Chem 1987; 263: 9844-9.

30 Hoyland J, Thomas J T, Marriott A, et al. Distribution of type $\mathrm{X}$ collagen mRNA in normal and osteoarthritic human cartilage. Bone $\mathcal{E}$ Mineral 1991; 15: 151-64.

31 von der Mark K, Kirsch T, Aigner T, et al. The fate of chondrocytes in osteoarthritic cartilage: regeneration, differentiation or hypertrophy? In: Kuettner K, differentiation or hypertrophy? In: Kuettner K, Biochemistry of articular cartilage. New York: Raven Press, Biochemistry of
1992:221-34.

32 LuValle P, Ninomiya Y, Rosenblum N D, Olsen B R. The type $\mathrm{X}$ collagen gene: intron sequences split the 5 '-untranslated region and separate the coding regions for the non-collagenous amino-terminal and triple-helical domains. F Biol Chem 1988; 263: 18378-85.

33 Thomas J T, Cresswell C J, Rash B, et al. The human collagen $X$ gene: complete primary translated sequence and chromosomal localization. Biochem $\mathcal{f} 1991 ; 280$ : 617-23.

34 Kielty C M, Hulmes D J, Schor S L, Grant M E. Embryonic chick cartilage collagens. Differences in the low Mrspecies present in sternal cartilage and tibiotarsal articular species present in sternal cartilage and tibiot

35 Kwan A P L, Cummings C E, Chapman J A, Grant M E. Macromolecular organization of chicken type $X$ collagen in vitro. F Cell Biol 1991; 114: 597-604.

36 Sawada H, Konomi H, Hirosawa K. Characterization of the collagen in the hexagonal lattice of Descemet's membrane: its relation to type VIII collagen. $\mathcal{F}$ Cell Biol
1990; 110: 219-27. 
37 Kielty C M, Boot-Handford R P, Ayad S, Shuttleworth C A, Grant M E. Molecular composition of type VI collagen: evidence for chain heterogeneity in mammalian tissues and cultured cells. Biochem f 1990; 272: 787-95.

38 Chu M-L, Zhang R- $Z$, Pan T, et al. Mosaic structure of globular domains in the human type VI collagen $\alpha 3$ chain: similarity to von-Willebrand factor, fibronectin, actin, salivary proteins and aprotinin type proteinase inhibitors. EMBO f 1990; 9: 385 -93

39 Stokes D G, Saitta B, Timpl R, Chu M-L. Human $\alpha 3$ (VI) collagen gene: characterization of exons coding for the amino-terminal globular domain and alternative splicing in normal and tumor cells. F Biol Chem 1991; 266: 8626-33.

40 Kielty C M, Whittaker S P, Grant M E, Shuttleworth C A. Type VI collagen microfibrils - evidence for a structural association with hvaluronan. F Cill Biol 1992; 118: 979-90.

41 Bidanset D J, Guidry C, Rosenberg L C, Choi H U, Timpl R, Hook M. Binding of the proteoglycan decorin Timpl R, Hook M. Binding of the proteoglycan deco

42 Roth G J, Titani K, Hoyer L W, Hickey M J. Localization of binding sites within human von-Willebrand factor for monomeric type III collagen. Biochem 1986; 25: $8357-61$.

43 Mollenhauer J, von der Mark K. Isolation and characterization of a collagen-binding glycoprotein from chondrocyte membranes. $E M B B O F 1983 ; 2: 45-50$.

44 Pfaffle M, Ruggiero F, Hofmann $\mathrm{H}$, et al. Biosynthesis, secretion and extracellular localization of anchorin CII, a collagen-binding protein of the calpactin family. $E M B O$ f1 1988; $7: 2335-42$.

45 Paulsson $\mathrm{M}$, Heinegard D. Noncollagenous cartilage proteins: current status of an emerging research field. Collagen Rel Res 1984; 4: 219-29.

46 Argraves W S, Deak F, Sparks K J, Kiss I, Goetinck P F. Structural features of cartilage matrix protein deduced from cDNA. Proc Natl Acad Sci USA 1987; 84: 464-8.

47 Hinek A, Reiner A, Poole A R. The calcification of cartilage matrix in chondrocyte culture: studies of the
C-propeptide of type II collagen (chondrocalcin). $f$ (iell Biol 1987; 104: 1435-41

48 Chandrasekhar S, Laurie G W, Cannon F B, Martin G R, Kleinman $\mathrm{H} \mathrm{K}$. In vitro regulation of cartilage matrix assembly by a $M_{r} 54,000$ collagen-binding protein. Proc Natl Acad USA 1986; 83: $5126-30$.

49 Fife R S, Brandt K D. Identification of a high-molecularweight $(>400,000)$ protein in hyaline cartilage. Biochim Biophy's Acta 1984; 802: 506-14.

50 Hedbom E, Antonsson P, Hierpe A, et al. Cartilage matrix proteins: an acidic oligomeric protein (COMP) detected only in cartilage. F Biol Chom 1992; 267: 6132-6.

51 Dozin B, Descalzi F, Briata L, et al. Expression, regulation, and tissue distribution of the $\mathrm{Ch} 21$ protein during chicken embryogenesis. F Biol Chem 1992; 267: 2979-85.

52 varner H H, Furthmaver H, Nilsson B, it al. Chondronectin: physical and chemical properties. Arch Chondronectin: physical and chem
Biochem Biophys 1986; 243: 579-85.

53 Heinegard D, Larsson T, Sommarin Y, Franzen A, Paulsson M, Hedbom E. Two novel matrix proteins isolated from articular cartilage show wide distributions among connective tissues. F Biol Chem 1986; 261: $13866-72$.

54 Oldberg A, Antonsson P, I inblom K, Heinegard D. A collagen-binding $59 \mathrm{kDa}$ protein (fibromodulin) is structurally related to the small interstitial proteoglycans PG-S1 and PG-S2 (decorin). EMBO f 1989; 8: 2601-4.

55 Guidry C, Miller E J, Hook M. A second fibronectinbinding domain is present in collagen $\alpha$ chains. $\mathcal{F}$ Biol Chem 1990; 265: 19230-6.

56 Salter D M, Hughes D E, Simpson R, Gardner D L. Integrin expression by human articular chondrocytes. Brit f Rheumatol 1992; 31: 231-4

57 Melching L I, Roughley P J. A matrix protein of $M_{r} 55,000$ that accumulates in human articular cartilage with age. Biochim Biophys Acta 1990; 1036: 213-20.

58 Neame P J, Young C N, Treep J T. Isolation and primary structure of PARP, a $24 \mathrm{kD}$ a proline- and arginine-rich protein from bovine cartilage is closely related to the $\mathrm{NH}_{2}$ protein from bovine cartilage is closely related to the $\mathrm{NH}_{2-}$ terminal domain

59 Vaughan L, Huber S, Chiquet $\mathrm{M}$, Winterhalter $\mathrm{K} \mathrm{H}$. A major, six-armed glycoprotein from embryonic cartilage. EMBRO F 1987; 6: 349-53.

60 Gross J. The behavior of collagen units as a model in morphogenesis. I Biophys Biochem Cytol Suppl 1956; 2: 26.

61 Miller E J, Matukas V J. Chick cartilage collagen: a new type of $\alpha 1$ chain not present in bone or skin

62 Miller E J. Structural studies on cartilage collagen employing limited cleavage and solubilization with pepsin. Biochem 1972; 11: 4903-9.

63 Grant M E, Ayad S, Kwan A P L, Bates G P, Thomas J T, McClure J. The structure and synthesis of cartilage collagens. In: Glauert A, ed. The control of tissue damage. collagens. In: Glauert A, ed.

64 Ayad S, Marriott A, Morgan K, Grant M E. Bovine cartilage types VI and IX collagens. Characterization of their forms types VI and IX collagens. Characterizat
in vivo. Biochem $\mathcal{7} 1989 ; 262: 753-61$.

65 Ayad S, Marriott A, Morgan K, et al. Mammalian cartilage collagens: identification of their forms in vivo. In Maroudas A, Kuettner K, eds. Methods in cartilag research. London: Academic Press, 1990:33-6.
66 Dingle J T, Horsfield P, Fell H B, Barratt M E J. Breakdown of proteoglycan and collagen induced in pig articular cartilage organ culture. Ann Rhelm Dis 1975; 34: 303-11.

67 Bienkowski R S, Cowan .M J, McDonald J A, Crystal R G Degradation of newly synthesizd collagen. $7 \mathrm{Biol}$ (:/hm 1978; 253: +350-63.

68 Robins S P, Seibel M J, McLaren A M. Collagen marker in urine in human arthritis. In: Maroudas A, Kuettner K, eds. Methods in cartilage resiarch. London: Academic Press, 1990:348-52

69 Dodge G R, Poole A R. Immunohistochemical detection and immunochemical analysis of type II collagen degradation in human normal, rheumatoid and osteoarthritic articular cartilages and in explants of bovine articular cartilage culture with interleukin 1. I Clin Ineest 1989; 83: 6.47 61

70 Gibson G J, Schor S I., Grant $M$ E. Effects of matrix macromolecules on chondrocyte gene expression: synthesis of a low-molecular weight collagen species by cells cultured within collagen gels. F Cill Biol 1982; 93: $767-74$.

71 Benya D D, Shaffer J D. Dedifferentiated chondroctytes reexpress the differentiated collagen phenotype when cultured in agarose gels. (cill 1982;15: 1313-2i.

72 Bates G P. Schor S L, Grant M E. A comparison of the effects of different substrata on chondrocyte morphology and the synthesis of collagen types IX and $\mathrm{X}$ in vitro. In I Titro Cell Der Biol 1987; 23: 374-80.

73 Thomas J T, Grant M E. Cartilage proteoglycan aggregate and fibronectin can modulate the expression of type $\mathrm{X}$ collagen by embronic chick chondrocvtes cultured in collagen gels. Biosi Rep 1988; 8: 163-71

74 Thomas J T, Boot-Handford R P, Grant M E. Modulation of type $\mathrm{X}$ collagen gene expression by calcium $\beta$-glycerophosphate and levamisole: implications for a possible role for type $\mathrm{X}$ collagen in endochondral bone formation. f Cell Sci 1990; 95: 639-48.

75 Horton W E, Cleveland J, Rapp L, it al. An established rat cell line expressing chondrocyte properties. Exp (icll Res 1988; 178: $457-68$

76 Thenet S, Adolphe M. Immortalization of chondrocytes in culture. In: Maroudas A, Kuettner K, eds. Methods in cartiluge research. London: Academic Press, 1990:95-8.

77 Mandahl N, Heim S, Arheden K, Rvdholm A, Willen H, Mitelman F. Chromosomal rearrangements in Mitelman F. Chromosomal rearrangements

is Kadler K E, Hojima Y, Prockop D J. Assembly of collagen fibrils de novo by cleavage of the type I pC-collagen with procollagen C-proteinase. Assay of critical concentration demonstrates that collagen self-assembly is a classical example of an entropy-driven process. 7 Biol Chom 1987 ; 262: $15696-701$

79 Holmes D F, Chapman J A, Prockop D) J, Kadler K E. Growing tips of type I collagen fibrils formed in vitro are near-paraboidal in shape, implying a reciprocal near-paraboidal in shape, implying a reciprocal relationship between accretion
Acad Sci USA 1992; 89: $9855 \ldots 9$

80) Kadler K E, Torre-Blanco A, Adachi E, Vogel B E, Hojima Y, Prockop D J. A type I collagen with a substitution of a cysteine for glycine-748 in the $(x 1(\mathrm{I})$ chain copolymerizes with normal type I collagaen and can generate fractal-like structures. Biochim 1991; 30: j081-8.

81 Frischauf A M, Lehrach $\mathrm{H}$, Rosner C, Boedtker $\mathrm{H}$. Procollagen complementary DNA, a probe for messenger RNA purification and the number of type I collagen genes. Biochem 1978;17: 3243-9.

82 Sandell L. J, Boyd C D, eds. Extracellular Matrix Genes. San Diego: Academic Press, 1990

83 Erlich H A, ed. PCR technology: Principles and applications for DNA application. New York: Stockton Press, 1989.

84 Ferre F. Quantitative or semi-quantitative PCR: reality versus myth. PCR Mcth Applic 1992; 2: 1-9.

85 Peltonen J, Jaakkola S, Gay K, Olsen D R, Chu M-L, Citto J. Expression of extracellular matrix genes by cultured human cells: localization of messenger RNAs and antigenic epitopes. Anal Biochem 1989; 178: 184-93.

86 Capecchi M R. Altering the genome by homologous recombination Sciellic 1989; 244: 1288-92.

87 Vandenberg P, Khillan J S, Prockop D J, Helminen $H$ Kontusaari S, Ala-Kokko L. Expression of a partially Kontusaari $\mathrm{S}$, Ala-Koted gene of human type-II procollagen (COI.2A1) in deleted gene of human type-II procollagen (COI.2A1) in
transgenic mice produces a chondrodysplasia. Proc Nat transgenic mice produces a chondro
Acad Sci USA 1991; 88: 7640-44.

88 Nakata K, Ono K, Miyazaki J-L, et al. Osteoarthriti associated with mild chondrodysplasia in transgenic mice expressing $\alpha$ I (IX) collagen chains with a central deletion. Proc Natl Acad Sci USA 1993; 90: 2870-4.

89 Jacenko O, Lu Valle P A, Olsen B R. Spondylometaphyseal dysplasia in mice carrying a dominant negative mutation in a matrix protein specific for cartilage-to-bone transition. Nature 1993; 365: 56-61.

90 Prockop D J, Kivirikko KI. Heritable diseases of collagen New Engl f Med 1984; 311: 376-86.

91 Pelletier J-P, Martel-Pelletier J, Altman R D, GhandurMnaymneh L, Howell D S, Woessner J F. Collagenolytic activity and collagen matrix breakdown of the articular cartilage in the Pond-Nuki dog model of osteoarthritis. Arthritis Rheum 1983; 26: 866-74.

92 Nojima T, Towle C A, Mankin H J, Treadwell B V. Secretion of higher level of active proteoglycanases from human osteoathritic chondrocytes. Arthritis Rheum 1986; 29: 292-95. 